(C) Copyright 2012 American Meteorological Society (AMS). Permission to use figures, tables, and brief excerpts from this work in scientific and educational works is hereby granted provided that the source is acknowledged. Any use of material in this work that is determined to be "fair use" under Section 107 of the U.S. Copyright Act or that satisfies the conditions specified in Section 108 of the U.S. Copyright Act (17 USC §108, as revised by P.L. 94-553) does not require the AMS's permission. Republication, systematic reproduction, posting in electronic form, such as on a web site or in a searchable database, or other uses of this material, except as exempted by the above statement, requires written permission or a license from the AMS. Additional details are provided in the AMS Copyright Policy, available on the AMS Web site located at (http://www.ametsoc.org/) or from the AMS at 617-227-2425 or copyright@ametsoc.org. 


\title{
Observational Analysis of Cloud and Precipitation in Midlatitude Cyclones: Northern versus Southern Hemisphere Warm Fronts
}

\author{
CATHERINE M. NAUD \\ Columbia University, New York, New York \\ DEREK J. PosSELT \\ University of Michigan, Ann Arbor, Michigan \\ SusAn C. VAN DEN HEEVER \\ Colorado State University, Fort Collins, Colorado
}

(Manuscript received 3 October 2011, in final form 12 January 2012)

\begin{abstract}
Extratropical cyclones are responsible for most of the precipitation and wind damage in the midlatitudes during the cold season, but there are still uncertainties on how they will change in a warming climate. A ubiquitous problem among general circulation models (GCMs) is a lack of cloudiness over the southern oceans that may be in part caused by a lack of clouds in cyclones. This study analyzes CloudSat, CloudAerosol Lidar and Infrared Pathfinder Satellite Observations (CALIPSO), and Advanced Microwave Scanning Radiometer for Earth Observing System (AMSR-E) observations for three austral and boreal cold seasons, and composites cloud frequency of occurrence and precipitation at the warm fronts for Northern and Southern Hemisphere oceanic cyclones. The authors find that cloud frequency of occurrence and precipitation rate are similar in the early stage of the cyclone life cycle in both the Northern and Southern Hemispheres. As cyclones evolve and reach their mature stage, cloudiness and precipitation at the warm front increase in the Northern Hemisphere but decrease in the Southern Hemisphere. This is partly caused by lower amounts of precipitable water being available to Southern Hemisphere cyclones, and smaller increases in wind speed as the cyclones evolve. Southern Hemisphere cloud occurrence at the warm front is found to be more sensitive to the amount of moisture in the warm sector than to wind speeds. This suggests that cloudiness in Southern Hemisphere storms may be more susceptible to changes in atmospheric water vapor content, and thus to changes in surface temperature than their Northern Hemisphere counterparts. These differences between Northern and Southern Hemisphere cyclones are statistically robust, indicating A-Train-based analyses as useful tools for the evaluation of GCMs in the next Intergovernmental Panel on Climate Change (IPCC) report.
\end{abstract}

\section{Introduction}

Extratropical cyclones produce the bulk of the coldseason precipitation in middle and high latitudes and are key contributors to the meridional transport of energy between the equator and the poles. Though the largescale structure and evolution of these storms are well understood, it is still unclear what effect changes to the earth's climate will have on these systems. This is in part due to the complex interaction between a projected

Corresponding author address: Catherine Naud, Columbia University, 2880 Broadway, New York, NY 10025.

E-mail:cn2140@columbia.edu poleward shift in the storm track, increased atmospheric water vapor content (and consequent increases in latent heat release), and potential changes in the large-scale modes of variability (e.g., the southern annular mode; Solomon et al. 2007). The results of general circulation model (GCM) simulations of future climates indicate a decrease in the number of extratropical cyclones but disagree on future changes in their intensity (Lambert and Fyfe 2006; Bengtsson et al. 2009). Examination of reanalysis datasets from recent decades indicates a decrease in the number and an increase in the intensity of storms (e.g., Simmonds and Keay 2000; Graham and Diaz 2001). Analysis of $25 \mathrm{yr}$ of cloud observations reveal a poleward shift of the storm tracks in the Northern 
and Southern Hemispheres ( $\mathrm{NH}$ and $\mathrm{SH}$, respectively) of an amplitude much larger than predicted by current GCMs (Bender et al. 2012). Persistent uncertainties in cyclone modeling are in no small part because frontal scales cannot be fully resolved at the current spatial resolution of most GCMs.

In addition to disagreement on changes to storm structure, most GCMs produce cloud amounts in midlatitude oceans that are too low compared with observations. This may explain a tendency for most of the models that formed the basis of the Intergovernmental Panel on Climate Change's Fourth Assessment Report to overestimate the amount of solar radiation absorbed in midlatitude oceans (Trenberth and Fasullo 2010). Naud et al. (2010) found that one general circulation model did not form enough clouds across cold and warm fronts, partly because of its coarse spatial resolution. Another model tested by Field et al. (2011) was also found to produce less clouds poleward of the low than observed with CloudSat (Stephens et al. 2002). It is unclear whether anomalously large oceanic solar absorption is predominantly due to insufficient storm activity or to deficient representation of cloud processes. A consistent result from the aforementioned studies is the fact that this problem appears to be particularly acute over the southern oceans, though progress in this region has been hampered by a relative lack of data from groundbased observing systems.

Satellite observations have been used to study the precipitation and cloud distributions in midlatitude cyclones, but most studies have focused on the Northern Hemisphere (Lau and Crane 1995, 1997; Klein and Jakob 1999; Bauer and Del Genio 2006; Naud et al. 2006). These, along with more recent studies that have examined both hemispheres (Field and Wood 2007; Gordon and Norris 2010), have employed passive instrumentation that provides information only at cloud top. Active instruments that provide full atmospheric profiles have recently been used to study cloudiness and radiative fields in the southern oceans (Mace 2010; Haynes et al. 2011), but cyclones were not specifically studied. Berry et al. (2011) recently reported significant asymmetry in the occurrence of fronts in the Southern and Northern Hemispheres, but they did not analyze cloud and precipitation fields associated with these regions. Govekar et al. (2011) studied the three-dimensional distribution of clouds and precipitation using active instruments in Southern Hemisphere cyclones, but no comparison was made to their northern counterparts.

The results presented by Berry et al. (2011) highlight the fact that, while the processes that lead to cyclone formation are not expected to differ between the two hemispheres, intrinsic geographic differences may cause differences in cyclones that will affect their associated cloud and precipitation fields. For example, Eckhardt et al. (2004) found that most cyclones in the $\mathrm{NH}$ winter were accompanied by a strong warm conveyor belt, but this was not always the case in the $\mathrm{SH}$ winter. Such differences include the presence of a land-sea contrast and mountains in the Northern Hemisphere, and the proximity of Antarctica to the Southern Hemisphere storm track. Differences in topography and land-ocean distribution also affect the amplitude and propagation of upper-tropospheric-lower-stratospheric Rossby waves, which in turn affect cyclone structure and evolution. If improvements are to be made to GCM representations of midlatitude cloudiness, it is first necessary to understand 1) the morphological differences between Northern and Southern Hemisphere storms, 2) the processes that underlie these differences, and 3) the sensitivity of cyclone clouds and precipitation to changes in the environment.

To the best of our knowledge, a study of the differences in cloud and precipitation between Northern and Southern Hemisphere cyclones that includes a view of the internal structure of frontal clouds has not yet been conducted. Such an analysis is now possible using a stream of new observations that offer a three-dimensional view of the distribution of cloud and precipitation in midlatitude cyclones. In this study, we use observations from three instruments in the National Aeronautics and Space Administration (NASA)'s A-Train constellation to investigate the difference in cloud occurrence and precipitation across warm fronts and in the warm sector of Northern and Southern Hemisphere cyclones. Cloud vertical profiles are obtained jointly from the active radar and lidar sensors on CloudSat (Stephens et al. 2002) and Cloud-Aerosol Lidar and Infrared Pathfinder Satellite Observations (CALIPSO) (Winker et al. 2009), and liquid water path, precipitable water vapor, and precipitation rate are retrieved from the Advanced Microwave Scanning Radiometer for Earth Observing System (AMSR-E; Kawanishi et al. 2003).

We focus our attention on the warm frontal portion of the storm, as this region produces most of the precipitation in the cyclone (e.g., Eckhardt et al. 2004), and is characterized by copious cloud cover. In addition, warm fronts comprise the poleward end of the warm conveyor belt airstream, which transports moisture from the boundary layer on the equatorward side of the cyclone to the upper troposphere on the poleward side of the cyclone, and is the mechanism responsible for most of the precipitation (Eckhardt et al. 2004). We only consider cold-season cyclones, to avoid the inclusion of mesoscale summer-specific systems, and focus only on oceans, to avoid comparing land systems from the 
(a)

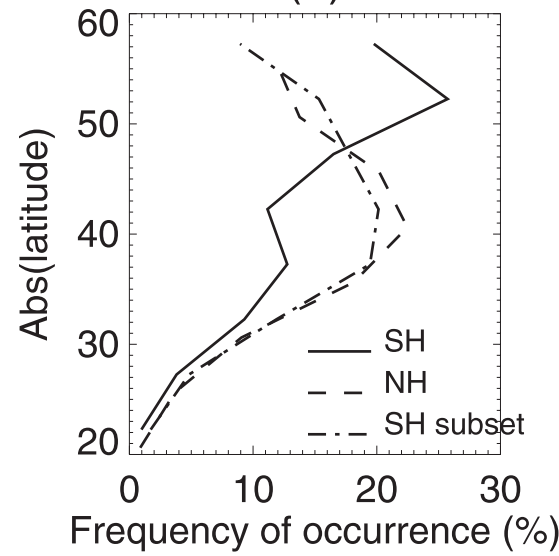

(b)

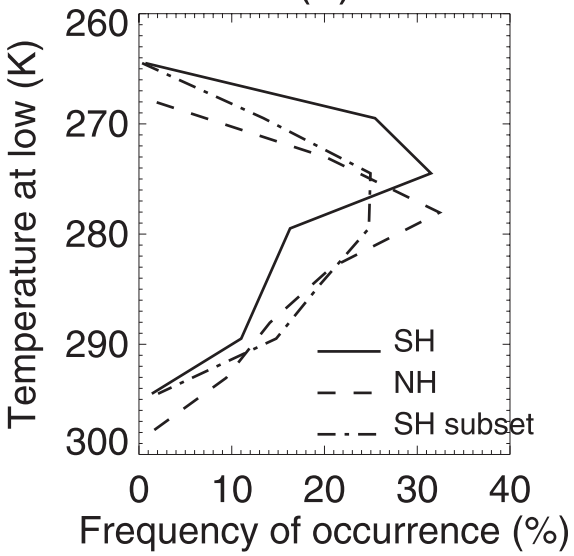

FIG. 1. Distribution of (a) cyclone centers as a function of absolute latitude in the NH (dashed) and SH (solid) midlatitude regions and (b) temperatures at the low pressure center. The dotted-dashed line shows the SH subset distribution obtained by randomly selecting $\mathrm{SH}$ cyclones in $5^{\circ}$ latitude bands until their number matches the NH dataset.

northern midlatitudes with ocean systems in the southern midlatitudes. Using NASA's Modern-Era Retrospective Analysis for Research and Applications (MERRA; Rienecker et al. 2011) outputs, we first constrain the dynamics and thermodynamics of Northern and Southern Hemisphere cyclones, and then we proceed to a comparison of the observed cloudiness and precipitation distribution.

\section{Datasets}

The CloudSat cloud profiling radar (CPR) provides full vertical profiles of cloud location. The vertical cloud mask is produced in synergy with the cloud mask of the lidar Cloud-Aerosol Lidar with Orthogonal Polarization (CALIOP) on board CALIPSO. The lidar is more sensitive to thin and tenuous clouds but gets attenuated in thick clouds and as such is a perfect complement to cloud radar observations. The joint cloud mask product is called geometrical profile (GEOPROF)-lidar (Mace et al. 2009) and provides cloud locations at $250-\mathrm{m}$ vertical and $1.1-\mathrm{km}$ horizontal (along track) resolution. In addition, surface rain rates retrieved from the CloudSat CPR are available in the precipitation column (PRECIP-COLUMN) files (Haynes et al. 2009).

Coincident measurements from AMSR-E provide two-dimensional views of retrieved precipitable water [here referred to as precipitable water vapor (PWV); Wentz and Meissner 2004], liquid water path (LWP), and surface precipitation rate (Wilheit et al. 2003). In our analysis, retrievals are only used if over ice-free oceans. Radars perform better than microwave radiometers for light rain but the latter are better for heavy rain. Use of both instruments allows us to incorporate a wide range of precipitation types.

To complement the A-Train observations, we use the MERRA reanalysis (Rienecker et al. 2011) outputs of temperature, geopotential heights, relative humidity $(\mathrm{RH})$, vertical velocity $(\omega)$ and horizontal wind profiles, along with skin temperature and mean sea level pressure (SLP) every $6 \mathrm{~h}$ at a resolution of $0.5^{\circ} \times 0.667^{\circ}$ (except for $\mathrm{RH}$ and $\omega$, which are available at $1.25^{\circ} \times$ $1.25^{\circ}$.

Finally, the NASA Modeling, Analysis and Prediction (MAP) Climatology of Midlatitude Storminess (MCMS; Bauer and Del Genio, 2006) database provides the location and track of midlatitude cyclones for the entire period covered by the European Centre for MediumRange Weather Forecasts Interim Re-Analysis (ERAInterim; Dee et al. 2011). The MCMS algorithm looks for sea level pressure local minima (within a $3 \times 3$ grid box area) and tracks them over time. To be retained in the database, cyclones must travel less than $720 \mathrm{~km}$ between two 6-hourly time steps but, during their lifetime, must travel a total of at least $700 \mathrm{~km}$, last at least $24 \mathrm{~h}$, and reach a minimum in sea level pressure no greater than $1010 \mathrm{hPa}$. Here, we decided to call "cyclone" each individual 6-hourly snapshot along the track. For example, a system that lasted 2 days and was detected for eight consecutive 6-hourly time steps will provide eight "cyclones" in our database.

The observations and reanalysis fields are collected for three austral cold seasons [May-September (MJJAS) for 2007-09] and three boreal cold seasons [NovemberMarch (NDJFM) for 2006-09) over oceans in the latitude bands $20^{\circ}-60^{\circ} \mathrm{N} / \mathrm{S}$. 
(a) NH: MSLP and $\theta_{850 \mathrm{mb}}$

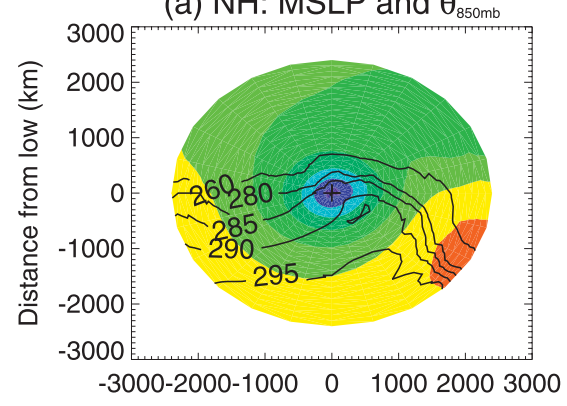

(c) SH: MSLP and $\theta_{850 \mathrm{mb}}$
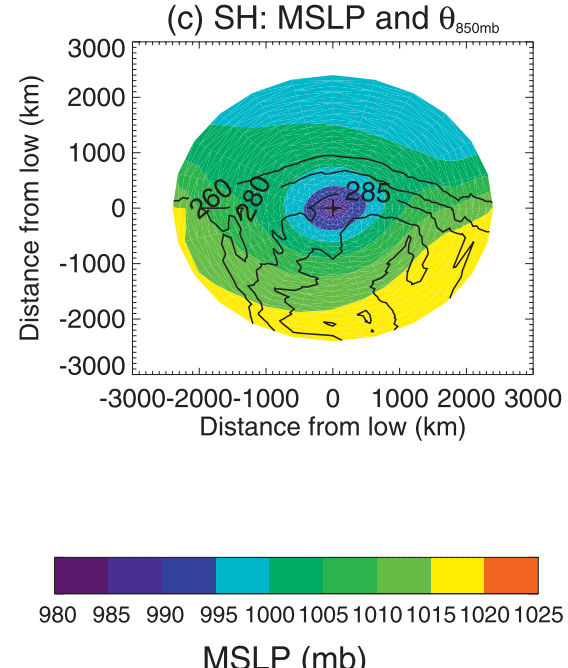

(b) $\mathrm{NH}: \omega_{500 \mathrm{mb}}$ and $\mathrm{Z}_{500 \mathrm{mb}}$

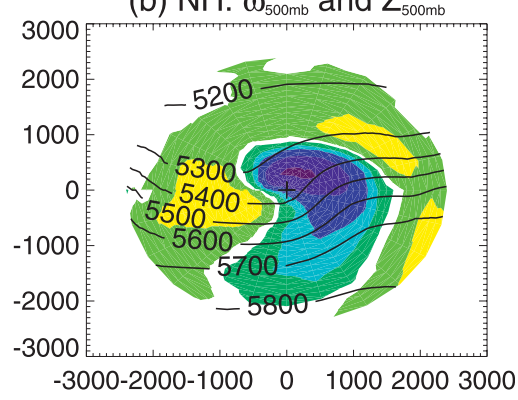

(d) $\mathrm{SH}: \omega_{500 \mathrm{mb}}$ and $Z_{500 \mathrm{mb}}$
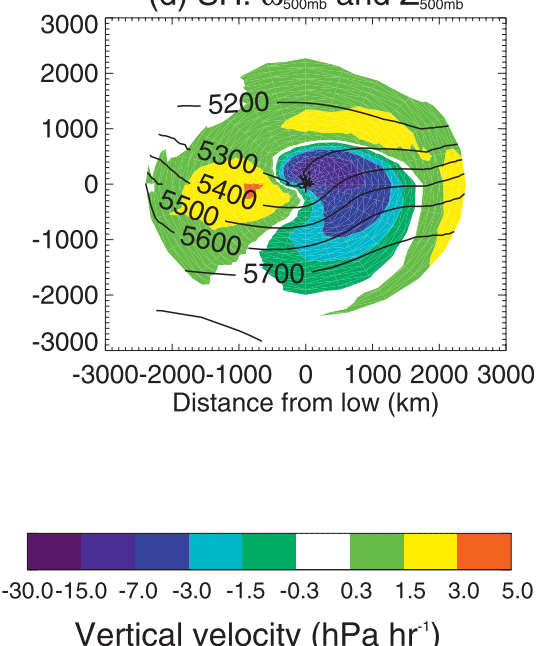

Vertical velocity ( $\left.\mathrm{hPa} \mathrm{hr} \mathrm{h}^{-1}\right)$

FIG. 2. Composites of (left) MERRA SLP with $\theta_{850 \mathrm{mb}}$ and (right) $\omega_{500 \mathrm{mb}}$ with $Z_{500 \mathrm{mb}}$ for (a),(b) NH and (c),(d) SH cyclones. Each field is rotated to align the warm front along the $x$ axis, and the rotation angles are similarly distributed between the two hemispheres. The northsouth axis is flipped for SH cyclones.

\section{Method}

The location of warm fronts is first determined using MERRA 850-mb temperature and geopotential heights based on a method introduced by Hewson (1998). The fronts are located using the spatial rate of change of the gradient of $850-\mathrm{mb}$ potential temperature. The divergence of this quantity should be null at the front. In addition, Hewson (1998) suggests also applying two masks, one that ensures that the gradient is large enough and the other that the rate of change of the gradient is above a minimum threshold. Warm and cold fronts are located using these three conditions. The warm fronts are then paired with a MCMS low pressure center if the nearest MCMS low is to the west and within $15^{\circ}$ of the center of the front. We then check if there is an intersection between this front and the CloudSat orbit within $\pm 3 \mathrm{~h}$. We only retain cyclones with a center over the ocean, and also remove cyclones for which the entirety of the warm front is over land (this mostly affects the eastern side of the Northern Hemisphere ocean basins but has the added advantage of removing the influence of the Rocky Mountains on frontal detection). Finally, because we do not want to include polar lows or tropical depressions, we exclude cyclones occurring poleward of $60^{\circ}$ or equatorward of $20^{\circ}$ latitude.

For the three austral cold seasons, warm front transects were identified in 1442 SH oceanic cyclones and in $574 \mathrm{NH}$ oceanic cyclones during the three boreal cold seasons. Figure 1a shows the distribution of cyclone center latitudes in absolute value in both hemispheres. For our comparison, we would like to avoid biases due to 1) large differences in sample size and 2) very different latitudinal distributions. To compare mean cyclone properties and processes that occur at the scale of a given cyclone, we need to reduce the impact of large-scale differences as much as possible. Specifically, cyclones close to $60^{\circ} \mathrm{N} / \mathrm{S}$ or $20^{\circ} \mathrm{N} / \mathrm{S}$ are exposed to different moisture amounts, surface temperature, and tropopause height, so we constrain the absolute latitude 
distributions so they are comparable between the two hemispheres. This ensures that the cyclones do not form in significantly different dynamical environments. To do so, we subsample the $\mathrm{SH}$ dataset by randomly selecting cyclones in $5^{\circ}$ (absolute) latitude bands until the number of SH cyclones per band is approximately equal to the number of $\mathrm{NH}$ cyclones in the same band. This resulted in 581 cyclones in the SH subset. The dotted-dashed line in Fig. 1a shows the distribution of cyclone center latitudes for the random subset of SH cyclones and demonstrates how the $\mathrm{NH}$ and $\mathrm{SH}$ subset cyclones are similarly distributed. Figure $1 \mathrm{~b}$ shows the cyclone pressure center skin temperature distribution for the $\mathrm{NH}$, $\mathrm{SH}$ full set, and the $\mathrm{SH}$ subset. Temperatures near low pressure centers in the $\mathrm{SH}$ random subset are very similar to those in the NH dataset, though it can be seen that $\mathrm{SH}$ temperatures are consistently a few degrees colder. Unless otherwise stated, the SH subset will be used for comparison with the $\mathrm{NH}$ for the remainder of this study. Although the full SH dataset will not be used for comparison with the $\mathrm{NH}$, we find that the differences described below between the $\mathrm{NH}$ and the $\mathrm{SH}$ subset are significantly greater than the differences we find between the full SH dataset and the SH subset (not shown).

Three types of composites are used. First, we construct two-dimensional vertical transects along the perpendicular to and centered on the warm front. CloudSat-CALIPSO cloud frequency of occurrence transects are composited this way. Similarly, CloudSat surface precipitation rates are composited along a line perpendicular to the front. For these two types of composites, because the CloudSat orbit is not strictly perpendicular to the warm fronts (the average angle is $70^{\circ}$ $\pm 25^{\circ}$ in the $\mathrm{SH}$ and $66^{\circ} \pm 29^{\circ}$ in the $\mathrm{NH}$ ), the observations are sorted based on their distance to the warm front and averaged into a grid of $0.2^{\circ}$ horizontal resolution and $250-\mathrm{m}$ vertical resolution. A more detailed explanation is available in Naud et al. (2010). Note that since the intersection can occur at a wide range of distances from the low, our composite includes transects that are in the zone of maximum precipitation, as well as transects close to the eastern edge of the warm front. Because the distribution of distances between the intersection and the low center is very similar between the two hemispheres (not shown), this decision has negligible impact on our conclusions. The third kind of composite is the cyclone centered plan view (e.g., Bauer and Del Genio 2006; Naud et al. 2006; Field and Wood 2007), which is used here for AMSR-E retrievals and MERRA fields. These composites are constructed here on a polar grid, with coordinates defined by the angle from the warm front and the radial distance from the low pressure center. This allows us to align the warm fronts along the horizontal axis, and to plot the data on an equidistant grid. The angle of rotation is similar between the two hemispheres, with a standard deviation of about $20^{\circ}$ and an average of less than $1^{\circ}$.

To some extent, the averages obtained in the composites depend on the method employed to select the observations and reanalysis fields. For example, the spatial resolution of the reanalysis temperatures used to detect the warm front locations matters, as the more precise the front location, the more precise the intersection with the CloudSat orbit. Thus, to evaluate if the differences we find between $\mathrm{NH}$ and $\mathrm{SH}$ composites are significant, we ran a series of tests in which we changed the inputs and their resolution before identifying warm fronts. Tests included the use of different spatial resolution $\left(0.5^{\circ}\right.$ vs $\left.1^{\circ}\right)$ in the reanalysis used to detect the fronts, different reanalysis temporal resolution (3 vs $6 \mathrm{~h}$ ), variations in the time difference between the front detection and the Cloudsat orbit (1.5 vs $3 \mathrm{~h}$ ), different sample sizes (100 vs 300 cyclones), different reanalysis data used for cyclone location (NCEP vs ERA-Interim), different reanalysis used for front detection (MERRA vs NCEP), and different setups for frontal detection (numerical technique, thresholds). These experiments yielded an ensemble of varying composites, and we used the maximum difference between all of the composites as a threshold above which differences between the $\mathrm{NH}$ and the SH can be deemed significant. This "noise level" was obtained for the CloudSat-CALIPSO cloud occurrence composite, the CloudSat precipitation, the AMSRE LWP, PWV, and precipitation rate, and MERRA 850 -mb winds. In addition, for the CloudSat cloud frequency composites, we assume a binomial distribution, assuming that all transects are independent realizations, and conduct a binomial test to keep only differences significant at the $95 \%$ level, as described in Naud et al. (2010). For AMSR-E PWV and MERRA 850-mb wind speeds, the distribution per grid cell is lognormal and a Student's $t$ test is performed on the natural logarithm of the data. Only differences significant at the $95 \%$ are plotted. For the CloudSat precipitation rates, the distribution is exponential (i.e., Poisson process) and therefore for each column across the warm fronts we calculate the $95 \%$ confidence interval and deem the difference between the two sets of data to be significant at the $95 \%$ level if the two intervals do not overlap.

All cyclones with an A-Train warm front transect are sorted according to their age and divided into three distinct periods. Onset and peak divide equally the period between the first time the cyclone is detected and the time at which it reaches peak intensity (minimum in sea level pressure). Dissipation is defined as all the time steps from immediately after the peak until the last time the cyclone is detected. 


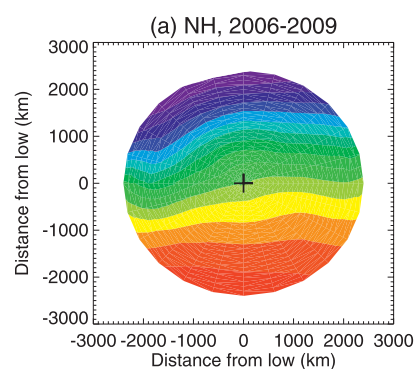

250253256259262265268271274277280283286289292295298 Skin temperature $(\mathrm{K})$ (b) SH, 2007-2009

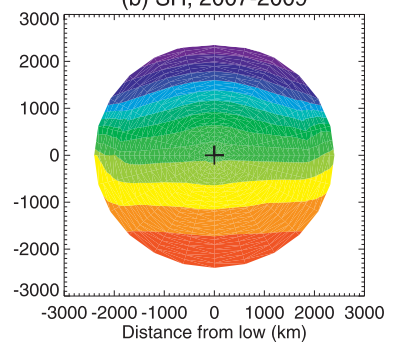

(1)

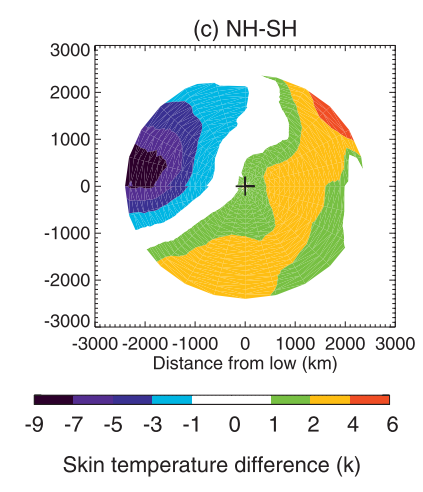

FIG. 3. Composite of MERRA skin temperature centered on cyclone low pressure for (a) $\mathrm{NH}$ and (b) $\mathrm{SH}$ subset cyclones; (c) difference in skin temperature composites between $\mathrm{NH}$ and $\mathrm{SH}$ cyclones.

\section{Comparison between NH and SH cyclones}

In this section, we compare the dynamics and skin temperature distribution of the cyclones for the whole $\mathrm{NH}$ dataset and the $\mathrm{SH}$ subset. We then proceed to partition both datasets according to cyclone age and reexamine the dynamic and thermodynamic characteristics, the systemwide precipitation rates and LWP, and the amount of clouds and accompanying surface precipitation at the warm front during onset and peak. We (a) $\mathrm{NH}$ onset

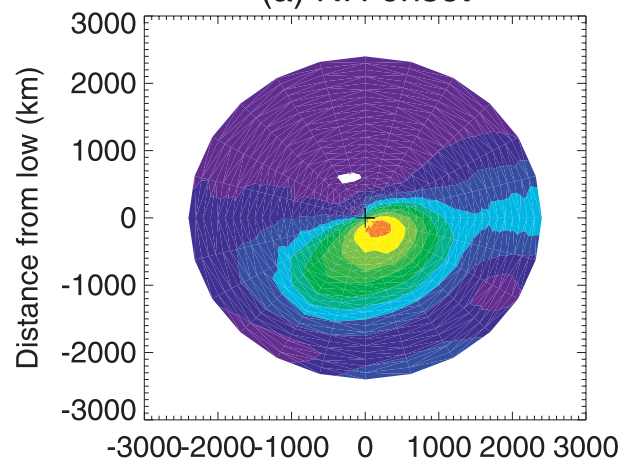

(c) $\mathrm{NH}$ peak

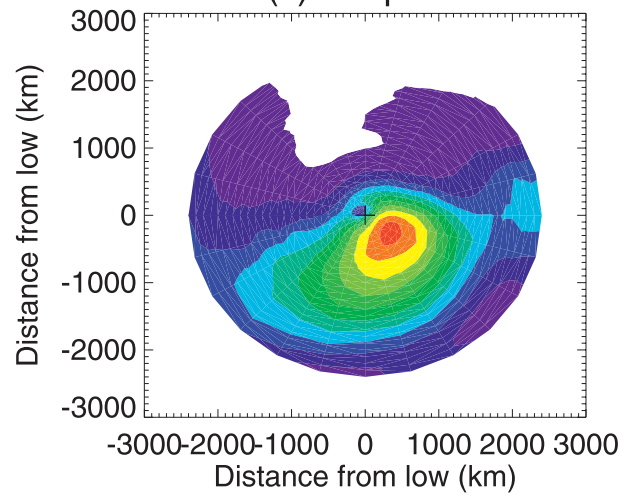

(b) $\mathrm{SH}$ onset

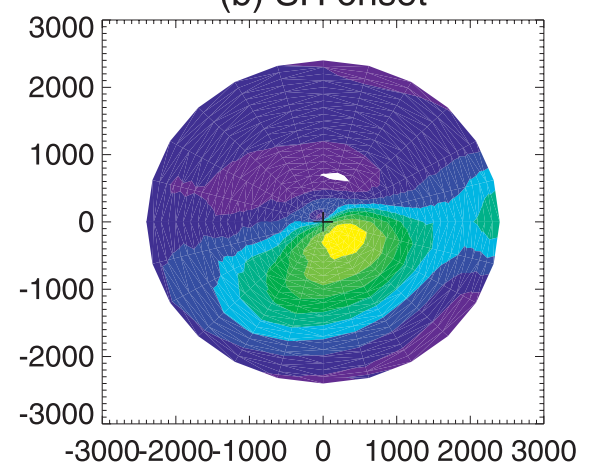

(d) SH peak

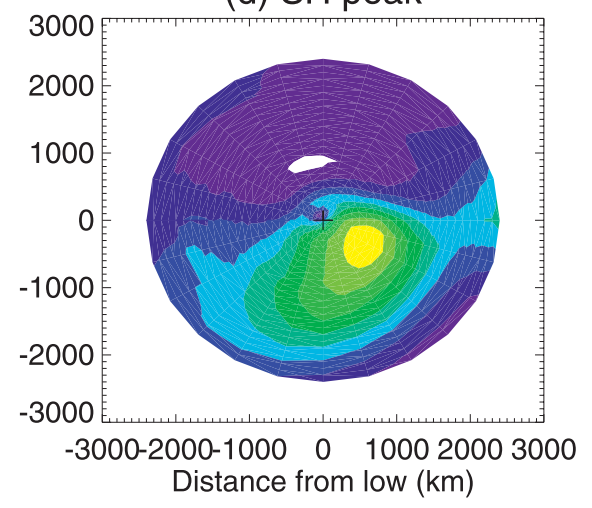

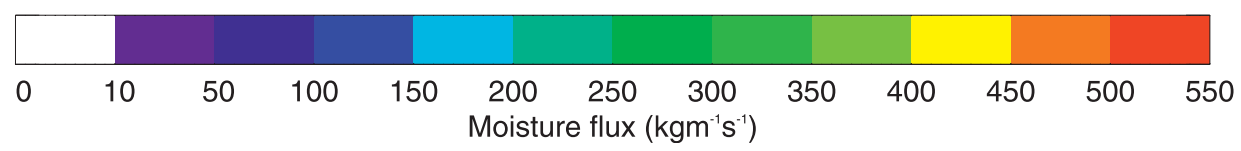

FIG. 4. Moisture flux composites for cyclones at (a),(b) onset and (c),(d) peak in (a), (c) NH and (b), (d) SH. 
(a) $\mathrm{NH}-\mathrm{SH}$ PWV onset

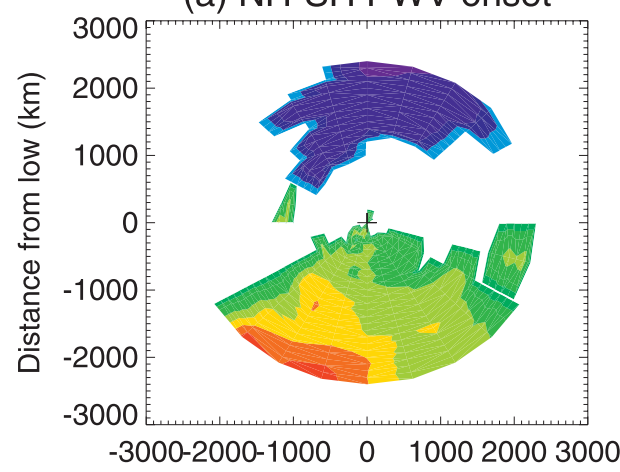

(c) $\mathrm{NH}-\mathrm{SH}$ wind onset

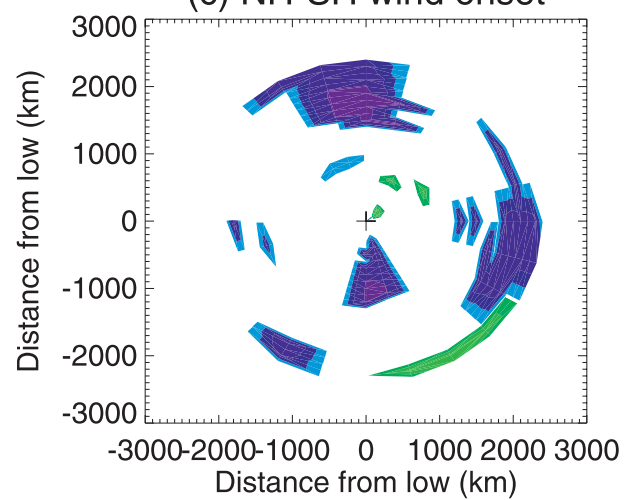

(b) NH-SH PWV peak

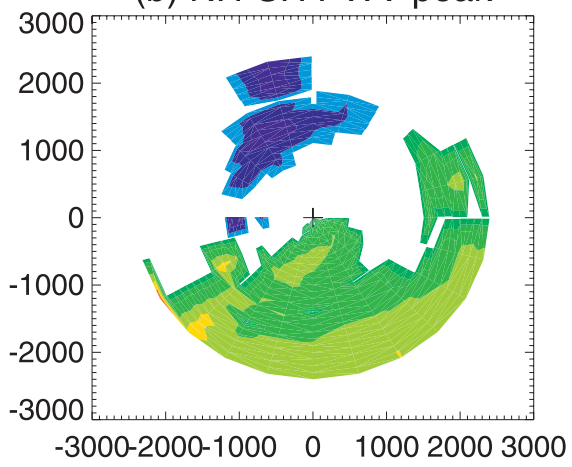

(d) $\mathrm{NH}-\mathrm{SH}$ wind peak

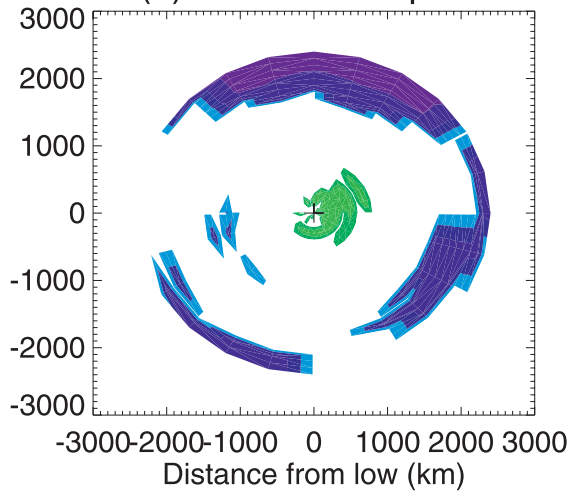

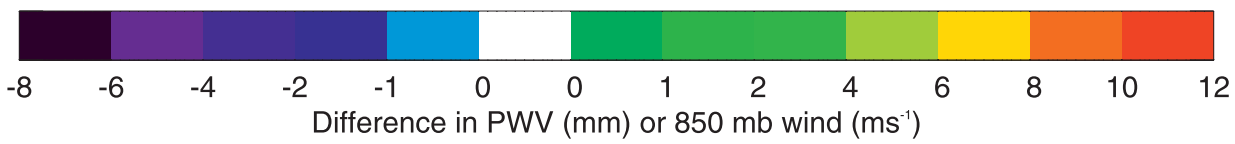

FIG. 5. Difference NH - SH in (a),(b) AMSR-E PWV and (c),(d) MERRA 850-mb wind speed at cyclone (a),(c) onset and (b),(d) peak when significant at the $95 \%$ level.

then compare cloudiness at the warm front when all of the cyclones are combined regardless of cyclone age.

\section{a. Comparison of cyclone dynamics and skin temperature}

The cyclone-centered composites of mean sea level pressure combined with composites of $850-\mathrm{mb}$ potential temperatures are shown in Fig. 2 alongside composites of 500-mb vertical velocity and $500-\mathrm{mb}$ geopotential heights for both the $\mathrm{NH}$ and $\mathrm{SH}$. Everywhere around the cyclone centers, mean sea level pressures are lower in the SH than the NH. This feature has been well documented, but, as Field and Wood (2007) explained, the deviation from the mean sea level pressure is equivalent between the two hemispheres. This equivalence in deviation is also observed in our datasets (not shown). There is a hint that the SLP distribution is more zonal in the $\mathrm{SH}$, and it seems that cyclones in the $\mathrm{NH}$ more often have a parent low to the northeast. The mean potential temperatures at $850 \mathrm{mb}$ are similar in value, but the composites reveal the region with the highest potential temperature occupies a narrower area equatorward of the low in the SH compared to the NH. The crossfront gradient in potential temperature is stronger in the $\mathrm{NH}$, and there is a much more pronounced thermal ridge in the Northern Hemisphere cases compared with the $\mathrm{SH}$.

Vertical velocity composites (Figs. $2 \mathrm{~b}$ and $2 \mathrm{~d}$ ) show ascending (negative omega) motions to the east of the low that extend westward and equatorward along the cold fronts and a zone of descending (positive) motion to the west of the low. The ascending velocities are more vigorous in the $\mathrm{NH}$ than the $\mathrm{SH}$, while the descending velocities are nearly identical, though there is a region of slightly larger downward vertical velocity west of the surface cyclone in the SH. The composite pattern of geopotential height at $500 \mathrm{hPa}$ is similar between the two 
(a) NH PWV

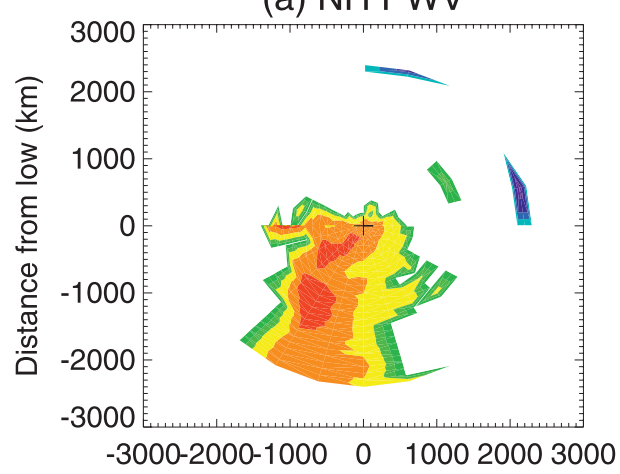

(c) $\mathrm{NH} 850 \mathrm{mb}$ wind

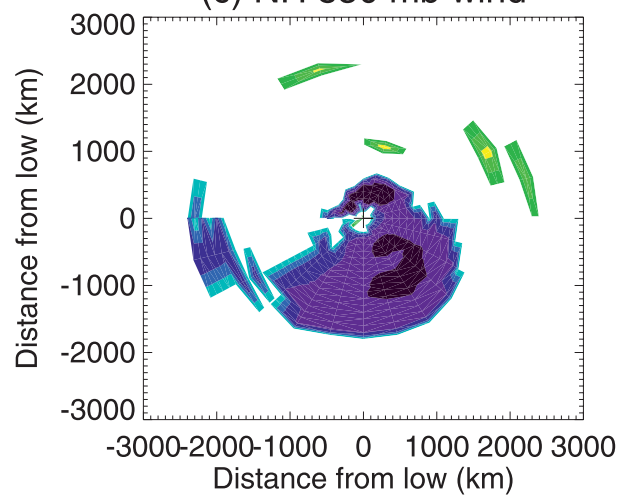

(b) SH PWV

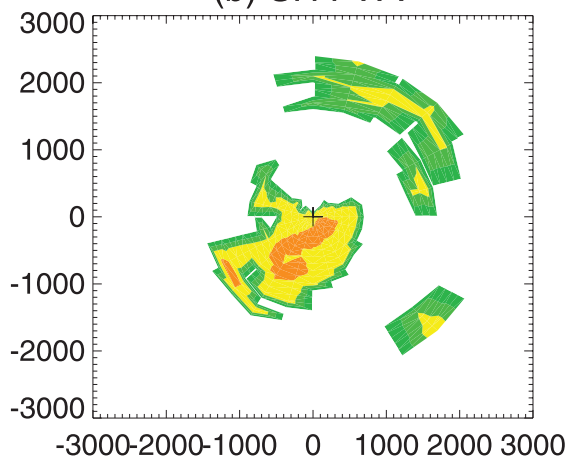

(d) $\mathrm{SH} 850 \mathrm{mb}$ wind

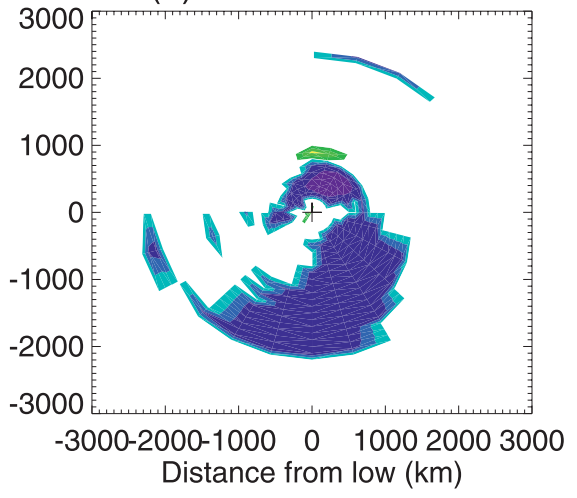

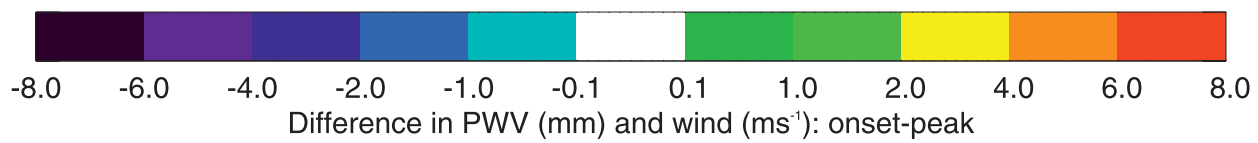

FIG. 6. Difference in (top) AMSR-E PWV and (bottom) MERRA 850-mb wind speed between cyclone onset and peak in (a),(c) NH and (b),(d) SH when significant at the $95 \%$ level.

hemispheres but with lower heights in the $\mathrm{SH}$ than the $\mathrm{NH}$, consistent with the difference in SLP.

The composites of MERRA skin temperature (Fig. 3) also show that the subsampling performed on the $\mathrm{SH}$ dataset produces a range in temperature that is similar between the two hemispheres. Consistent with plots of 850-hPa potential temperature (Fig. 2), the shape of the distribution differs, as a thermal ridge is more pronounced in the NH composite. Also, the subsampling of SH cyclones did not completely eliminate differences in warm-sector skin temperatures (Fig. 3c), but these are no greater than $4 \mathrm{~K}$, and only about half of the difference found between the $\mathrm{NH}$ and the full $\mathrm{SH}$ dataset (that exhibits a similar zonal distribution, albeit with colder temperatures; not shown). The more vigorous upward vertical motions in the $\mathrm{NH}$ and the wider region of warm potential and skin temperatures equatorward of the low suggest that poleward transports of moisture might be more vigorous in the $\mathrm{NH}$ than in the $\mathrm{SH}$.

\section{b. Cyclone life cycle}

Composite thermodynamic and vertical velocity fields indicate that, even if we constrain the $\mathrm{NH}$ and $\mathrm{SH}$ datasets so that they have similar latitudinal and temperature distributions on average, the cyclones are still dynamically different. Therefore, we now partition composites according to cyclone age as described above to examine whether differences are concentrated early or late in the cyclone life cycle.

There were 155 occurrences of cyclones at onset in the $\mathrm{NH}, 289$ at peak, and 111 in the dissipation stage for the three seasons examined, while there were 169 at onset, 266 at peak, and 146 at dissipation in the SH. The hemispheric frequencies are thus fairly consistent and each stage is equivalently represented. We find overall that $\mathrm{SH}$ cyclones travel a shorter distance in latitude than those in the NH dataset. This is contrary to the overall average per hemisphere when considering all the cyclones available in 
(a) $\mathrm{NH}$ onset

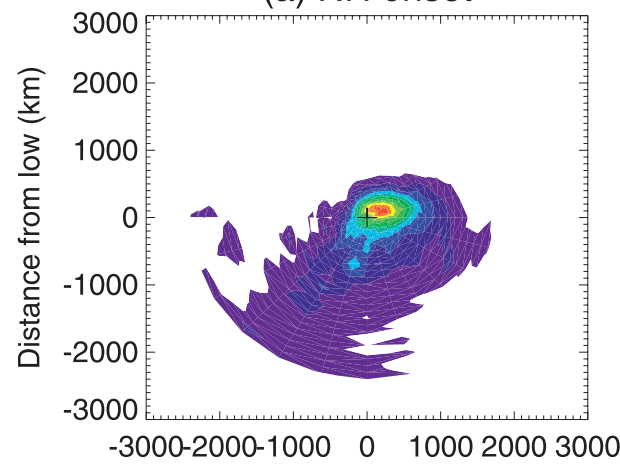

(c) $\mathrm{SH}$ onset

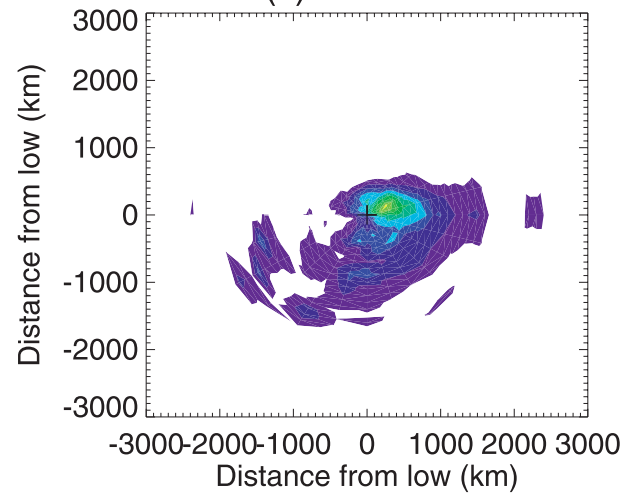

(b) NH peak

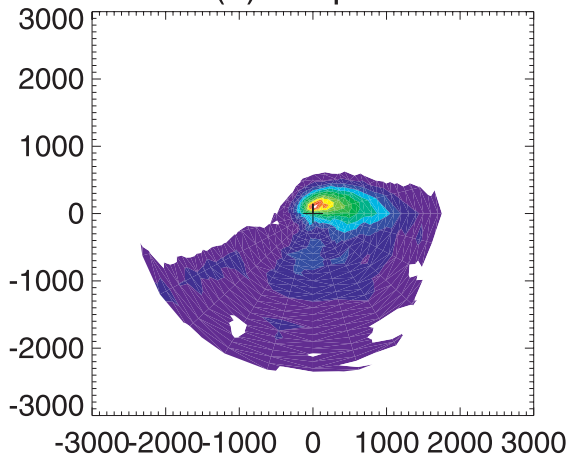

(d) $\mathrm{SH}$ peak

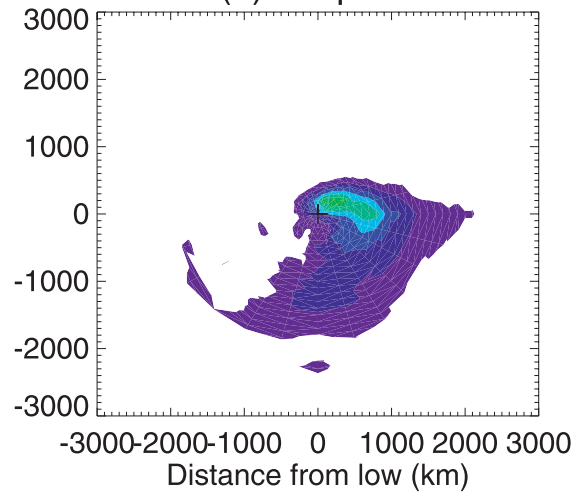

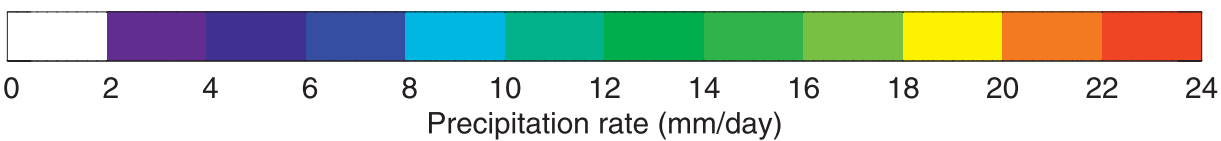

FIG. 7. AMSR-E precipitation rate composites at cyclone (a),(c) onset and (b),(d) peak for (a),(b) NH and (c),(d) SH.

the MCMS database, as $\mathrm{SH}$ cyclones tend to travel longer spans of latitude than $\mathrm{NH}$ cyclones. Because we retain only those cyclones that exhibit a strong enough temperature gradient for the warm front to be detected, our datasets contain the most active cyclones that apparently tend to travel longer meridional distances in the Northern Hemisphere.

We focus on onset and peak because 1) dissipation comprises a wide range of situations (various distinct stages of occlusion) and 2) the differences we find between the two hemispheres in the dissipation stage strongly resemble those described here for peak.

To examine the poleward transport of moisture at onset and peak in the warm sector, we calculate the moisture flux as the product of AMSR-E PWV and MERRA $850-\mathrm{mb}$ wind speed. Figure 4 shows the moisture flux composites for the $\mathrm{NH}$ and $\mathrm{SH}$ at onset and peak. Figure $4 \mathrm{a}$ and $4 \mathrm{~b}$ demonstrate how at onset the fluxes are similar in both hemispheres, with a slightly greater maximum close to the low in the $\mathrm{NH}$ but greater fluxes in the $\mathrm{SH}$ away from the low. In fact, at onset the $\mathrm{SH}$ winds are slightly stronger than in the $\mathrm{NH}$, although the difference is below the 95\% significance level (Fig. 5c). As such, the relatively lower amounts of PWV in the SH (Fig. 5a) may be compensated by slightly more vigorous winds (Fig. 5c) that allow the moisture flux to be similar to that of the NH. The larger differences in PWV far equatorward of the cyclone center at onset (Fig. 5b) likely reflect the poleward movement of NH storms; $\mathrm{NH}$ cyclones travel farther from the equator than do their SH counterparts.

The amount of moisture in the warm sector decreases throughout the cyclone life cycle in both hemispheres (Figs. 6a and 6b), in part because cyclones move poleward and thus away from typical water vapor source regions. The fact that the PWV does not change as much between onset and peak in the $\mathrm{SH}$ as in the $\mathrm{NH}$ may be due to a combination of a smaller meridional Southern 
(a) $\mathrm{NH}$ onset

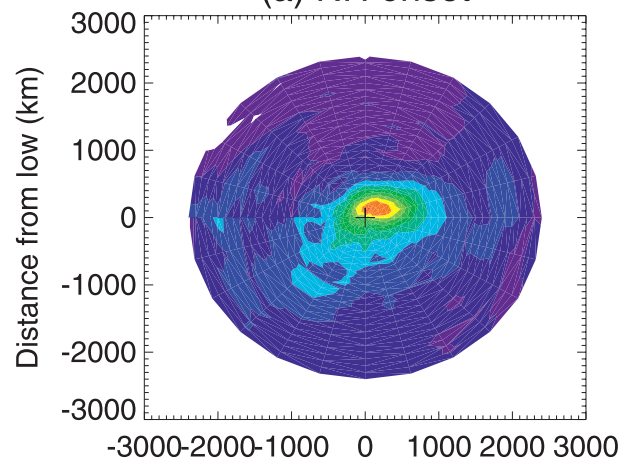

(c) SH onset

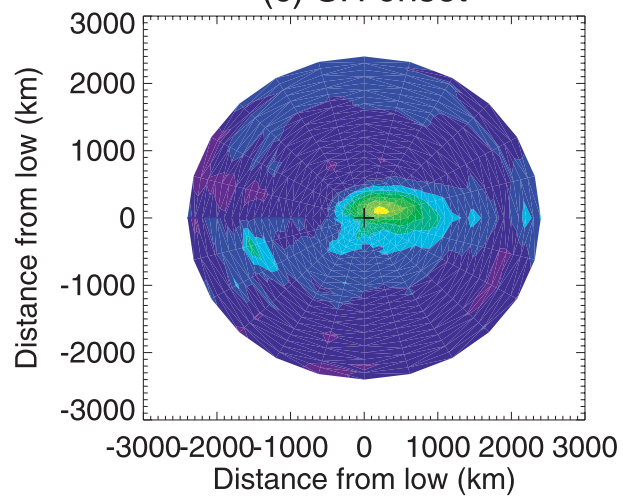

(b) $\mathrm{NH}$ peak

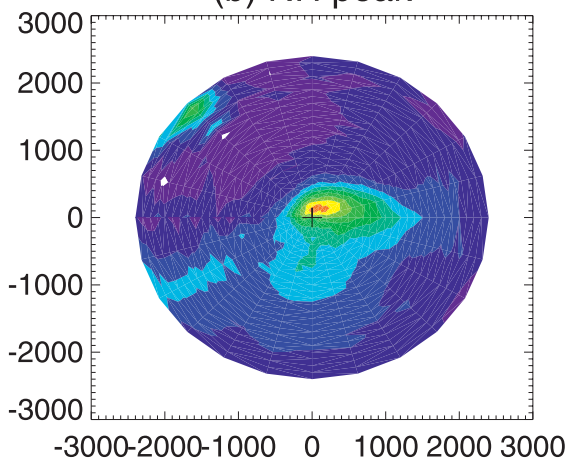

(d) $\mathrm{SH}$ peak

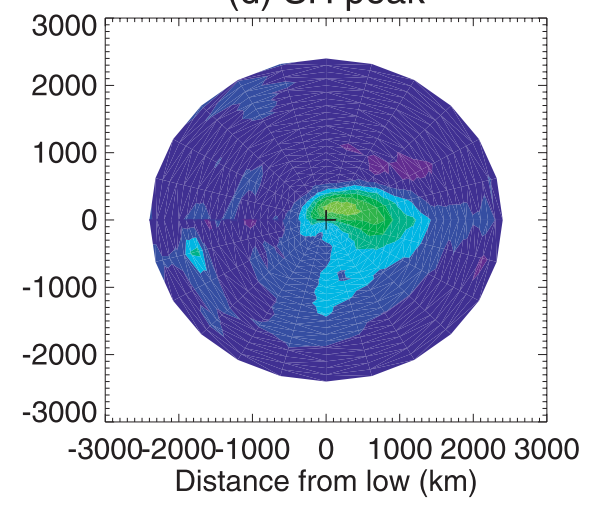

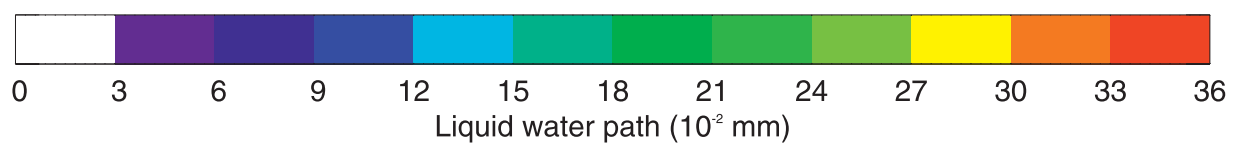

FIG. 8. As in Fig. 7, but for AMSR-E LWP composites.

Hemisphere PWV gradient, along with a more zonal trajectory for $\mathrm{SH}$ storms. In both hemispheres, the geographic extent of precipitation rates above $4 \mathrm{~mm}$ day $^{-1}$ and LWP above $0.12 \mathrm{~mm}$, for example, increase in the warm front and warm sector as the systems evolve $(+55 \%$ of the onset area and $+54 \%$, respectively, for the $\mathrm{NH}$; $+19 \%$ and $+46 \%$, respectively, for the $\mathrm{SH}$ ), but the overall magnitude decreases (Figs. 7 and 8 ). Simultaneously, wind speeds increase, with a maximum at peak (Figs. 6c and 6d), but the increase is much larger in the $\mathrm{NH}$ than in the SH. Recall that the cyclone mean wind speeds at peak and onset were very similar between the NH and SH (Fig. 5).

According to the study of Field and Wood (2007), cloud amount and precipitation in midlatitude cyclones are jointly dependent on PWV and low-level winds through the warm conveyor belt. As observed in Figs. 4 and 6, the large increase in wind speed as NH cyclones evolve compensates for the large decrease in moisture and suggests that $\mathrm{NH}$ cyclones are more sensitive to changes in wind speed than moisture. However, the opposite seems to be true for SH cyclones, where changes in moisture appear to be more influential on changes in moisture flux than are changes in wind speed. This will certainly have a direct impact on cloud occurrence at the warm front.

To examine the relative impact of wind and PWV on the warm front cloudiness, we partitioned the SH subset dataset in which all cyclones are included regardless of age into nine categories determined by the warm-sectoraveraged $850-\mathrm{mb}$ wind and PWV (the quadrant east and equatorward of the low pressure center). Figure 9 shows the cloud frequency of occurrence across warm fronts for these nine categories. An increase in cloud occurrence in the frontal tilt can be observed as PWV increases (from bottom to top rows). However, no clear change can be observed in the composites as wind speed increases (from left to right columns). This suggests that SH warm front cloudiness is more sensitive to moisture than wind. This result is sufficiently robust that we reach the same conclusion if we use thresholds in wind and 

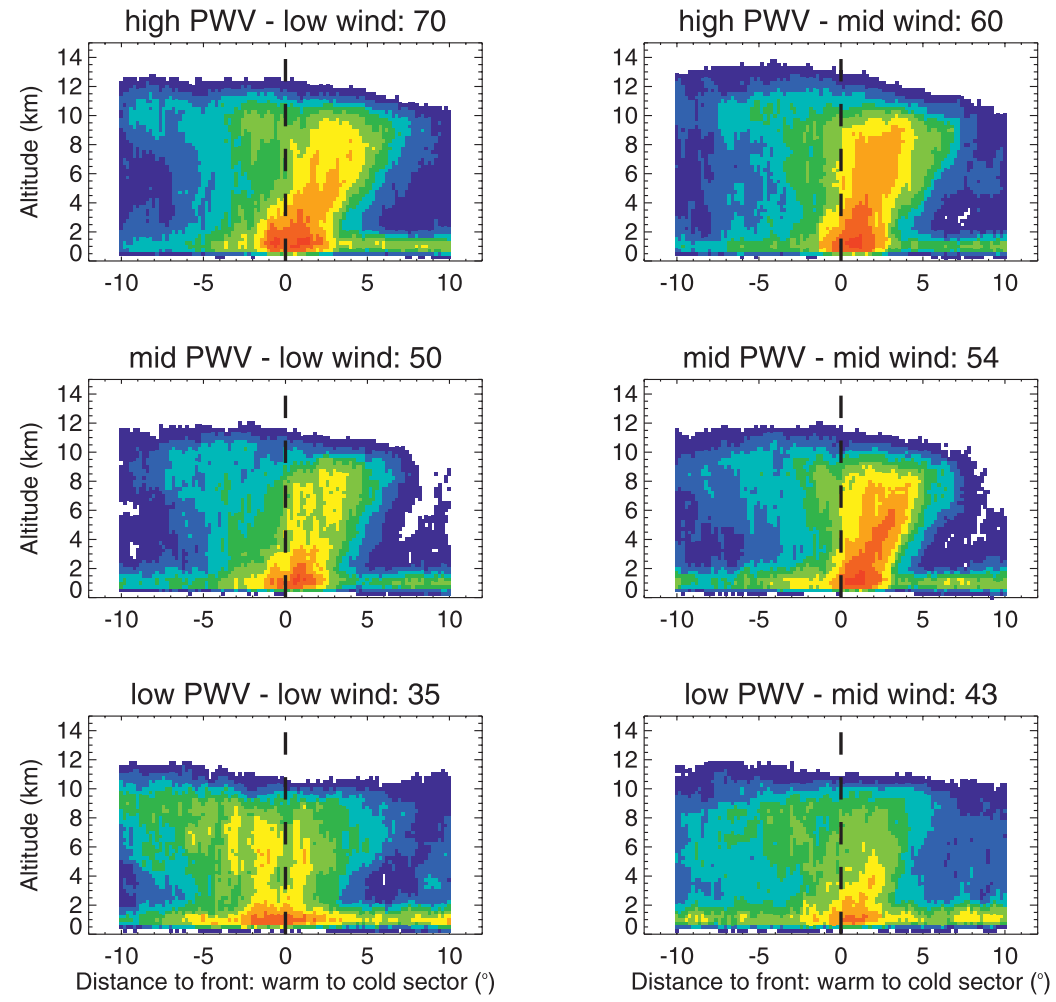
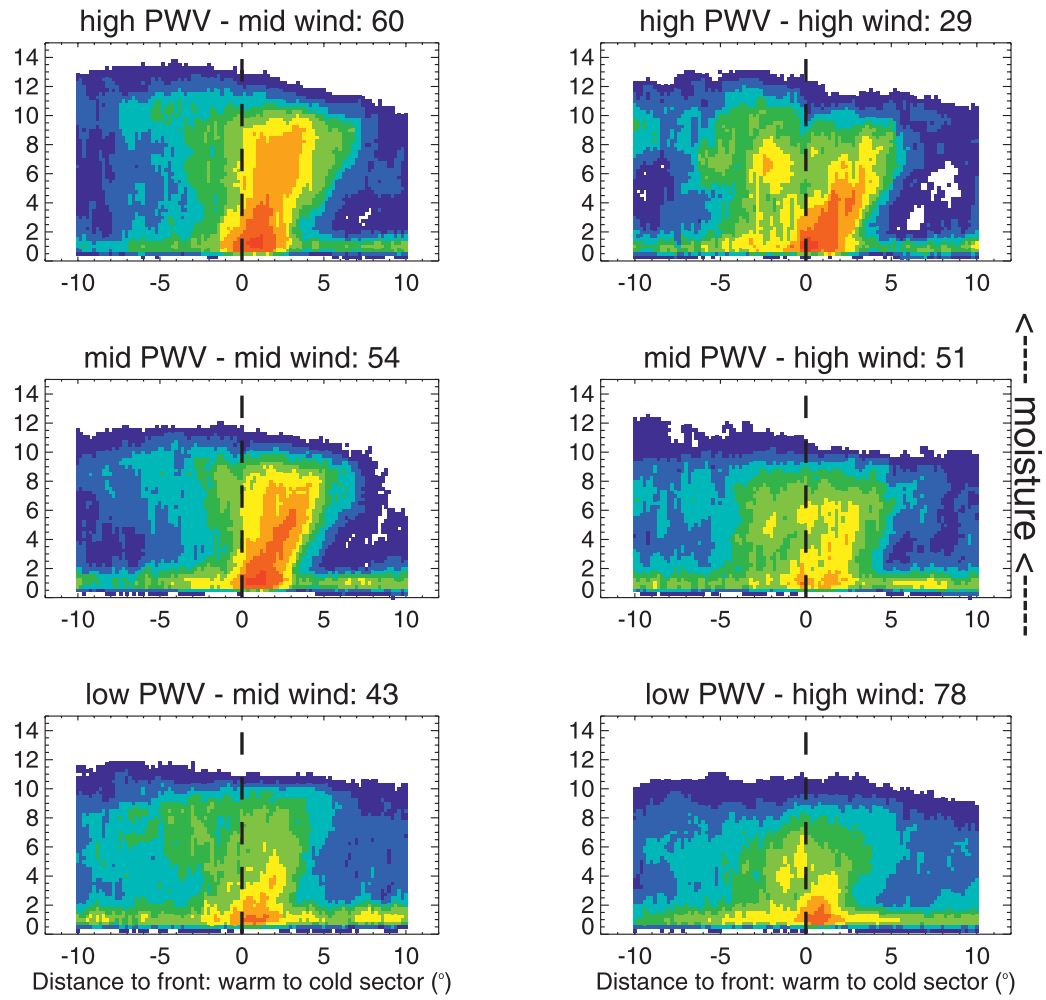

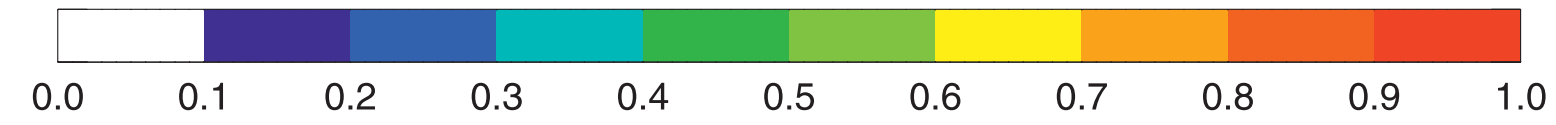

\section{CloudSat GEOPROF-LIDAR cloud frequency of occurrence: $\mathrm{SH}$ subset, $\mathrm{SH}$ thresholds}

FIG. 9. CloudSat-CALIPSO cloud frequency of occurrence across warm fronts for SH as a function of (left to right) wind speed and (bottom to top) PWV. The number of cyclones per subset is given at the top of each plot.

PWV established with the NH dataset, or if we use the entire SH dataset. A similar figure was created for the NH dataset but no clear dependency on either of the parameters was evident and thus is not shown here.

The implication is that cloudiness and precipitation at the warm front are similar between the two hemispheres at onset (Figs. 10 and 11), with slightly more frequent cloud occurrence in the $\mathrm{SH}$ at the highest altitudes. However, as the cyclone evolves, cloudiness at the warm front increases at the peak stage in the $\mathrm{NH}$ but remains relatively constant in the SH (Fig. 12), consistent with the moisture flux evolution (Fig. 4). Figures 10 and 12 only show differences significant at the $95 \%$ level according to a binomial statistical test. In the $\mathrm{NH}$, as cyclones evolve from onset to peak, most of the change in cloud frequency of occurrence occurs in the frontal tilt, where cloud occurrence increases between onset and peak
(Fig. 12a), whereas cloud occurrence in the SH frontal tilt changes very little, with a slight tendency to decrease (Fig. 12b). In contrast, cloud occurrence in the SH warm sector and poleward of the front increase significantly from onset to peak (Fig. 12b). In addition, NH cyclones have much larger amounts of cloud poleward of the warm front in the lower and middle troposphere, possibly reflecting a greater amount of precipitation in this region (Fig. 12a).

Consistent with differences in frontal cloud occurrence, mean precipitation rates increase in the $\mathrm{NH}$ between onset and peak but change little in the SH (Fig. 11). We verified that the small difference between onset and peak for cloud and precipitation in the frontal tilt is not caused by a close occurrence in time of onset and peak. In fact, SH cyclones classified as "onset" occur on average $36 \mathrm{~h}$ prior to centers classified as "peak." In addition, the 


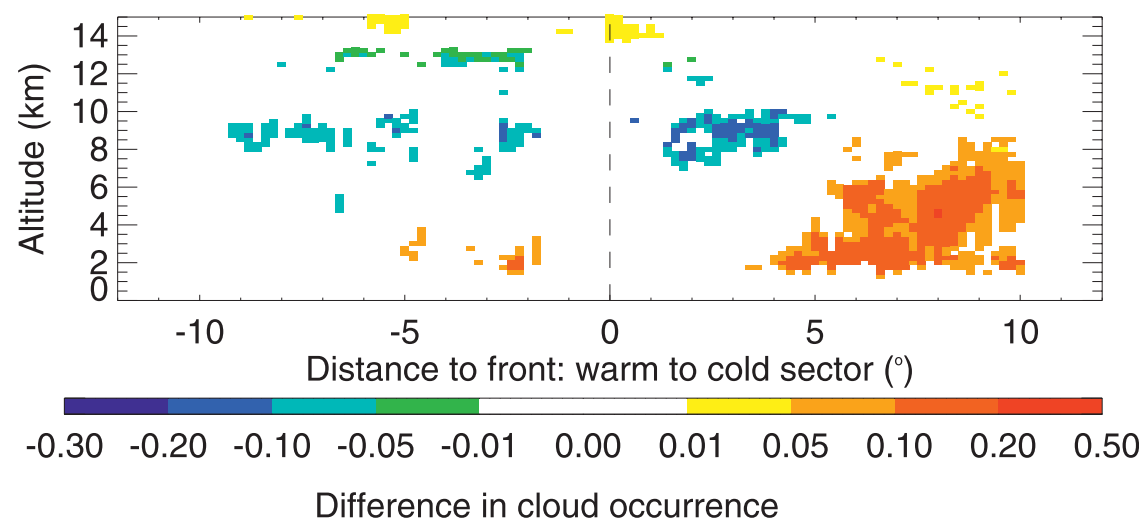

FIG. 10. Difference in CloudSat-CALIPSO cloud occurrence when significant at the $95 \%$ level at cyclone onset between $\mathrm{NH}$ and $\mathrm{SH}$.

maximum precipitation rate at onset is very similar between $\mathrm{NH}$ and $\mathrm{SH}$ storms, consistent with the similarity in frontal cloud occurrence, although the largest precipitation rates occur within a narrower band in the $\mathrm{SH}$ than in the NH. The greater NH peak precipitation rate continues into the dissipation phase. This suggests that $\mathrm{NH}$ and $\mathrm{SH}$ cyclones are very similar in the early stages of a cyclone lifetime, but that cloud distributions differ as the cyclones mature because of dynamic and thermodynamic differences in cyclone characteristics between the two hemispheres.

\section{c. Comparison of all cyclones}

In this section, we explore the implications of the differences associated with the cyclone stages on the overall cyclone properties for each hemisphere. We combine all cyclones collected in the original $\mathrm{NH}$ and $\mathrm{SH}$ subset datasets, regardless of their age. We then examine the average wind and PWV distributions, and the average cloud and precipitation distributions. We kept the constraint on the latitude distribution of the SH cyclones, so we do not include discrepancies caused by a much larger number of cyclones close to the polar circle in the SH.

The composites of AMSR-E PWV and MERRA 850-mb winds (Fig. 13) for both hemispheres depict the expected contrast in humidity between the poleward and equatorward portions of the cyclone, the poleward half being much drier than the equatorward half [consistent with the PWV composites of Field and Wood (2007)]. Overall, $\mathrm{PWV}$ is larger in the $\mathrm{NH}$ warm sector than in the $\mathrm{SH}$, and smaller poleward and westward of the warm front. These differences can be partly but not fully explained by the slight differences in skin temperature in the warm sector (Fig. 3) and reflect the differences (a) $\mathrm{NH}$

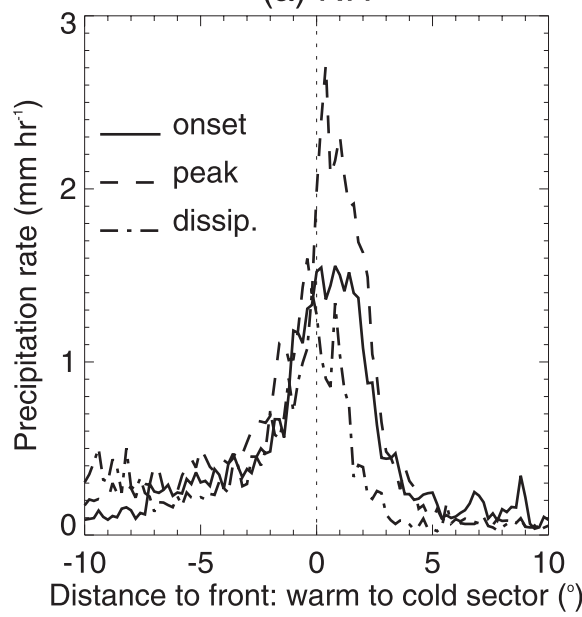

(b) $\mathrm{SH}$

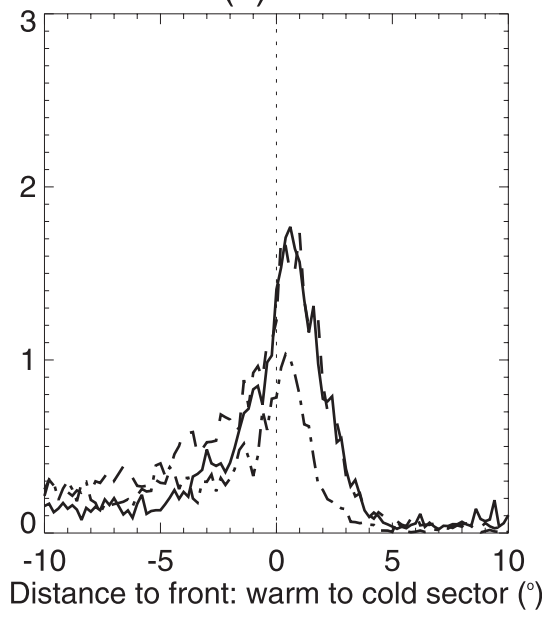

FIG. 11. CloudSat precipitation rate across warm fronts, for cyclone onset (solid), peak (dashed) and dissipation (dotted-dashed) in (a) NH and (b) SH. The dotted line marks the position of the surface front. 
(a) $\mathrm{NH}$

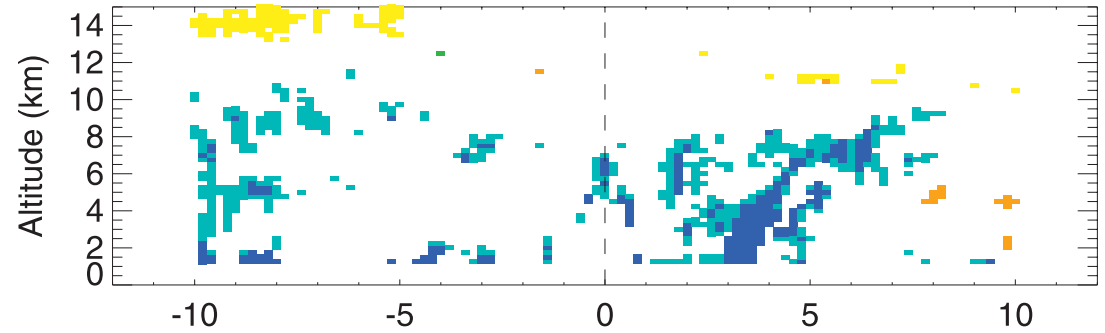

(b) $\mathrm{SH}$
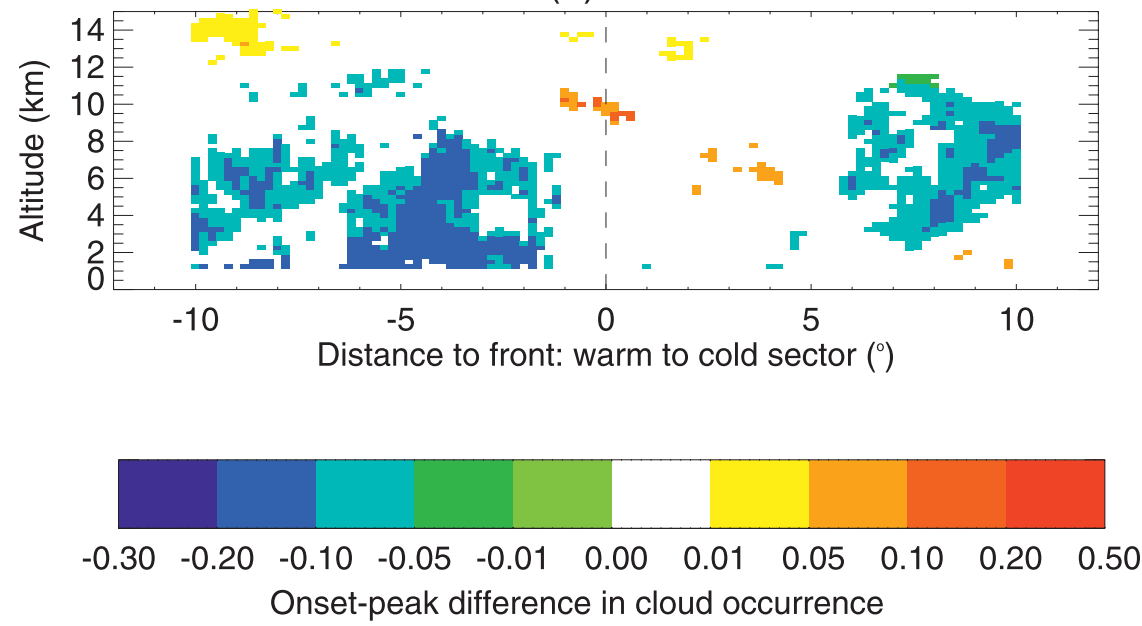

FIG. 12. Difference in CloudSat-CALIPSO cloud occurrence when significant at the $95 \%$ level between cyclone onset and peak in (a) NH and (b) SH. The dashed line marks the position of the surface front.

observed through the cyclone life cycles (Fig. 5). MERRA 850-mb winds reveal the flow in the poleward section of the SH cyclones to be more vigorous than in $\mathrm{NH}$ cyclones. The maximum in wind speed is immediately east of and on the equator side of the low, and is of similar magnitude in both hemispheres, consistent with the similarity in the magnitude of the SLP anomaly. However, the region containing relatively high wind speed (e.g., greater than $8 \mathrm{~m} \mathrm{~s}^{-1}$ ) is broader in the $\mathrm{SH}$ than in the NH.

Figure 14 shows the corresponding CloudSat-CALIPSO cloud frequency of occurrence for the $\mathrm{NH}$ and $\mathrm{SH}$ composited across warm fronts. The first two composites in Fig. 14 demonstrate that both hemispheres exhibit a very similar structural distribution of cloud occurrence. They both indicate a maximum in frequency at low levels across the front, although it should be noted that the observations are not reliable within the first $1 \mathrm{~km}$ above the surface because of high surface reflectance issues (Marchand et al. 2008). After the low levels, the next largest occurrence is seen at and in advance of the front and follows the frontal tilt. A relatively high frequency of occurrence of high-level clouds can also be seen across the front (see discussion in Naud et al. 2010). Note that the radar cannot distinguish suspended (cloud) from precipitating particles. Because precipitating particles are embedded within the clouds, the maximum in hydrometeor occurrence is found near the surface front in the zone where precipitation is at a maximum. Despite the structural similarity between frontal cloud fraction in the $\mathrm{NH}$ and $\mathrm{SH}$, the difference in cloud occurrence at peak has an impact on the amount of clouds present at the warm front overall (Fig. 14c). Differences in Fig. 14c are only plotted when significant at the $95 \%$ level according to a binomial test and when greater than the maximum difference found across the multiple tests described in section 3. There is a much larger frequency of cloud occurrence poleward of the surface front in the $\mathrm{NH}$, consistent with the greater amount of PWV in the $\mathrm{NH}$ warm sector. Differences are greatest in the frontal tilt, where clouds occur more often in the $\mathrm{NH}$ than $\mathrm{SH}$, especially along the poleward edge, where variability is greatest across cyclones, while there are more midlevel and highlevel clouds in the SH warm sector. Recall that, compared 
(a) NH: AMSR-E PWV

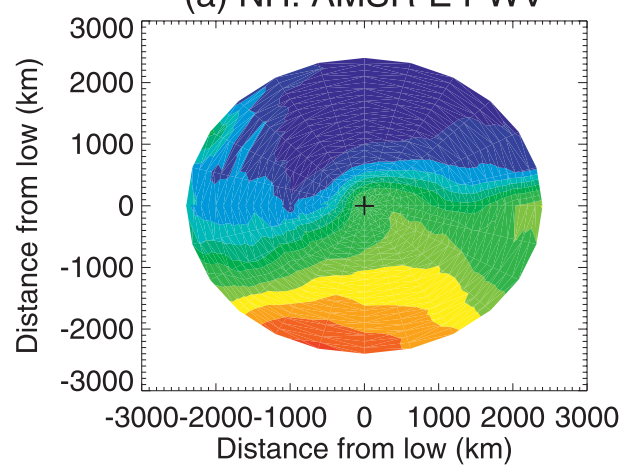

(c) SH: AMSR-E PWV

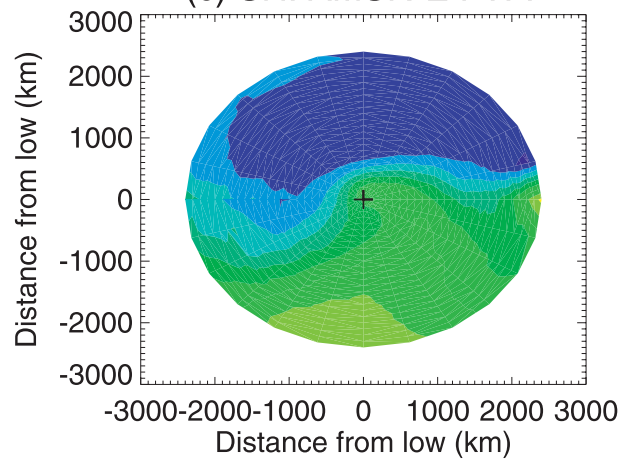

022468101214161820222426283032

PWV (mm) (b) $\mathrm{NH}$ : $850 \mathrm{mb}$ MERRA wind

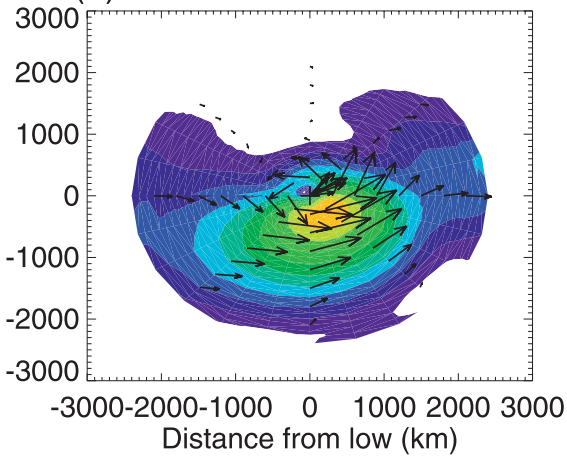

(d) SH: $850 \mathrm{mb}$ MERRA wind
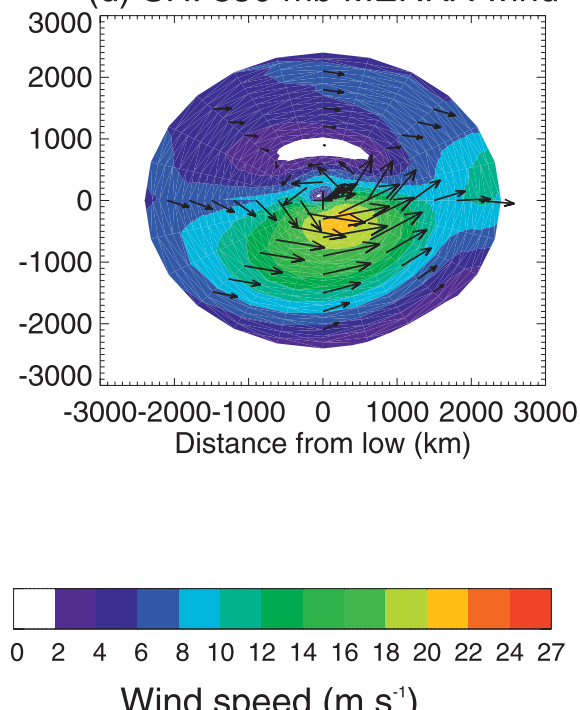

FIG. 13. Composites of (left) AMSR-E PWV and (right) MERRA 850-mb wind for (a),(b) NH and (c),(d) SH. The arrows in (b) and (d) indicate the wind direction, with the size of the arrows proportional to the wind speed.

with $\mathrm{SH}$ cyclones, $\mathrm{PWV}$ is greater in the $\mathrm{NH}$ warm sector but drier north of the warm front. Increased cloud frequency is consistent with this larger gradient in water vapor. Interestingly, we also observe greater frequency of shallow cloud at distances greater than $5^{\circ}$ poleward of the warm front in the $\mathrm{NH}$ compared with the SH. Haynes et al. (2011) noted the frequent occurrence of shallow clouds in the region poleward of the cyclone in the $\mathrm{SH}$ and highlighted the fact that a large fraction of these clouds produce precipitation.

Figure 15 shows composites of CloudSat surface precipitation across the warm front for the $\mathrm{NH}$ and $\mathrm{SH}$, as well as the difference between the two, with superimposed points representing where the difference is above the noise and significant at the $95 \%$ level. The difference between the $\mathrm{NH}$ and $\mathrm{SH}$ in precipitation rates is largest at the front and in the frontal zone in the cold sector, but small differences in advance of the front (Haynes et al. 2011; shallow precipitating clouds discussed above) are also significant. In the warm sector, the differences are small and rarely significant. These results are consistent with greater amounts of PWV (Fig. 13) and cloud (Fig. 14) in the $\mathrm{NH}$ warm fronts.

Finally, Fig. 16 shows the composite of AMSR-E precipitation rate for the entire cyclone. Consistent with the CloudSat observations, the maximum in AMSR-E precipitation rate is slightly to the east of the low and poleward of the warm front in both hemispheres. As shown by CloudSat, the precipitation rate in $\mathrm{SH}$ warm front regions is much lower and precipitation is less widespread.

Another difference between the two hemispheres concerns the occurrence of clouds in the warm sector (Figs. 12b and 14). Recall that the SH exhibits greater cloudiness in the warm sector (Fig. 14), and much larger 
(a) $\mathrm{NH}, 574$

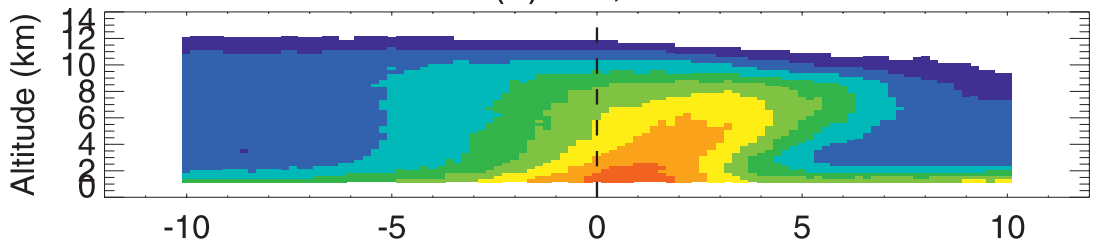

(b) $\mathrm{SH}, 581$

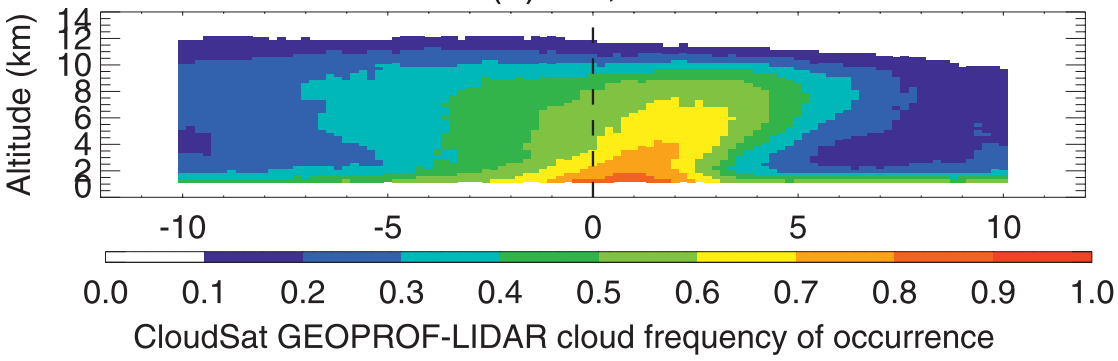

(c) $\mathrm{NH}-\mathrm{SH}$

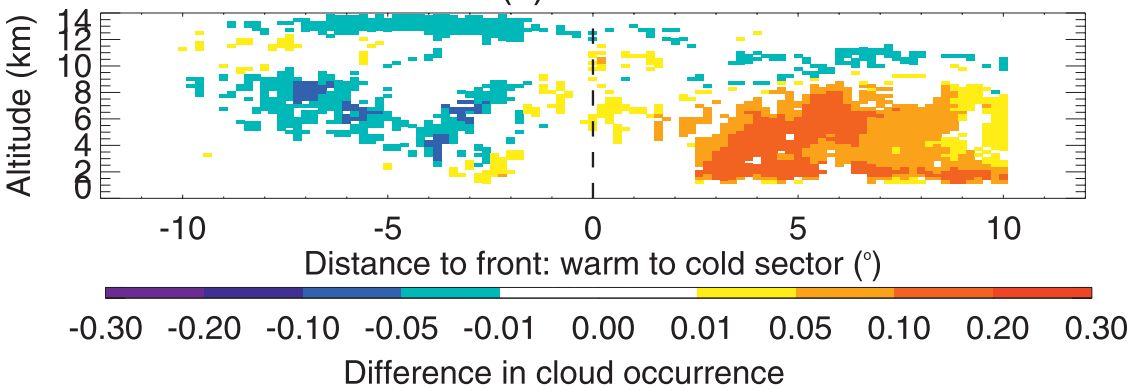

FIG. 14. CloudSat-CALIPSO cloud frequency of occurrence across warm fronts in (a) NH and (b) SH, with (c) difference in cloud occurrence between $\mathrm{NH}$ and $\mathrm{SH}$ when significant at the $95 \%$ level based on a binomial statistical test. The $x$ axis represents the distance in degrees from the surface front indicated by the dashed line. Positive values are in advance of the front and negative values in the warm sector.

warm-sector cloud fraction at peak relative to onset (Fig. 12b). These clouds may be generated by convection or alternately may be advected from the region of the cold front and could act as a PWV sink in SH. However, it is not possible to verify using the observations available to us whether the increase in warm-sector cloudiness is caused by increased convective activity at peak, and if so, whether this has any impact on the cloudiness at the warm front. Model-based analysis (e.g., Sinclair et al. 2010; Boutle et al. 2011) may provide an answer to this question.

\section{Conclusions}

We have performed an analysis of the differences between $\mathrm{NH}$ and $\mathrm{SH}$ cyclone structure and horizontal and vertical cloud distribution using information from ATrain satellites and MERRA reanalysis. We find that, when we constrain cyclones based on their age, the hemispheres display similar cloud and precipitation distributions in the early stages of a cyclone life. At onset, the cloud frequency and precipitation in the frontal zone are similar, presumably because lower PWVs in the $\mathrm{SH}$ warm sector are compensated by greater wind speeds. This implies that the warm conveyor belt moisture transport is efficient enough in the SH to maintain cloud formation and precipitation at the warm front, in a similar fashion to what is observed in the $\mathrm{NH}$. Between onset and peak, PWV decreases markedly in NH cyclones, but this decrease is more than compensated for by an increase in wind speed. As such, cloud occurrence and precipitation in frontal zones increases. In contrast, winds in SH storms do not increase as much as the storm matures and this, coupled with a decrease in PWV, leads to little or no change in warm front cloud frequency or precipitation. This in part explains the increased sensitivity of SH cyclones to changes in PWV compared to changes in wind speed. Consequently, overall, cloud frequency of occurrence and precipitation rate at and poleward of the warm front are generally lower in the $\mathrm{SH}$ than the $\mathrm{NH}$. This is 


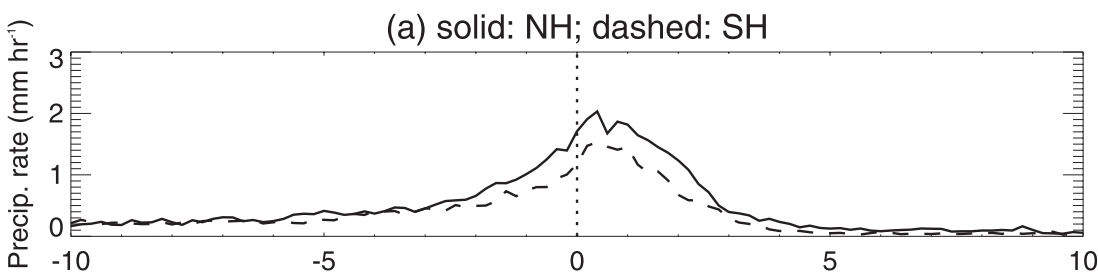

(b) (+): where significant

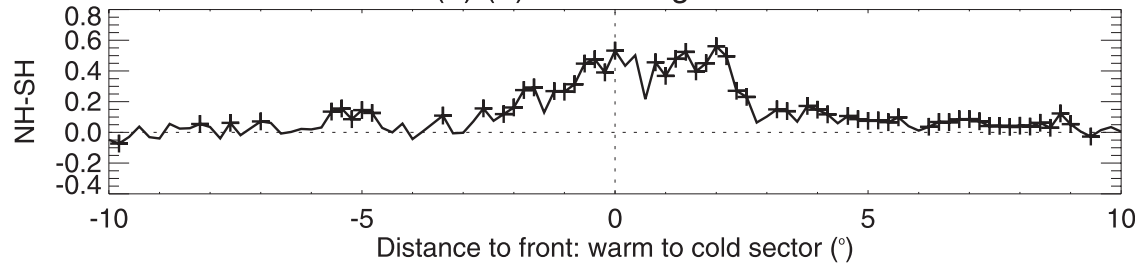

FIG. 15. (a) NH (solid) and SH (dashed) composites of CloudSat surface precipitation across warm fronts. The dashed line marks the location of the surface low. (b) Difference between NH and $\mathrm{SH}$ precipitation rate. The (+) symbol shows the difference in precipitation rate between $\mathrm{NH}$ and $\mathrm{SH}$ when it is above the variability caused by the method and significant at the $95 \%$ level.

accompanied by lower PWV in the warm sector, but slightly greater wind speeds at $850 \mathrm{mb}$ in the $\mathrm{SH}$.

The interplay between cyclone wind speed, warmsector PWV, and frontal precipitation rate and cloud occurrence has implications for the representation of cyclone-induced cloudiness in GCMs. Because of the greater sensitivity of $\mathrm{SH}$ cyclone cloud occurrence to changes in humidity, we speculate that in the context of a warming climate, changes in cloud cover in the southern midlatitudes may be greater than in the Northern Hemisphere, assuming that the number of cyclones changes similarly. Robust predictions of changes to extratropical cyclone frontal structure with changing climates will require GCMs to properly represent the interaction between cyclone dynamics, atmospheric water vapor content, and frontal clouds. Future work will comprise the use of the observational datasets employed in this study to evaluate GCMs (e.g., as part of the IPCC Fifth Assessment Report), not only for the amount of clouds and precipitation they produce in midlatitude cyclones, but also for their ability to reproduce the differences in the cyclone characteristics and location between the two hemispheres, as well as the sensitivity of the observed cloudiness to changes in moisture and winds. (a) $\mathrm{NH}$

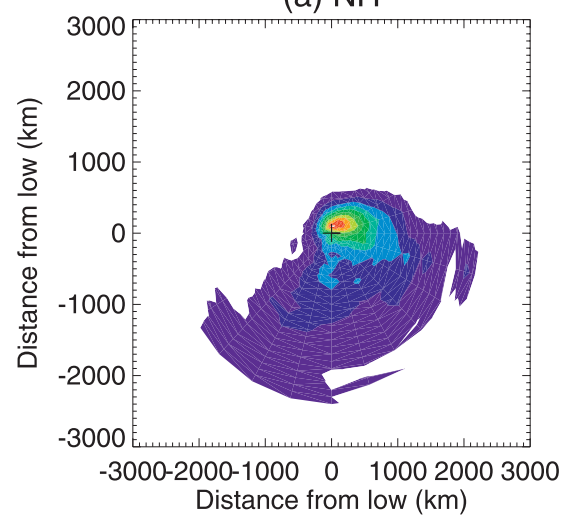

(b) $\mathrm{SH}$

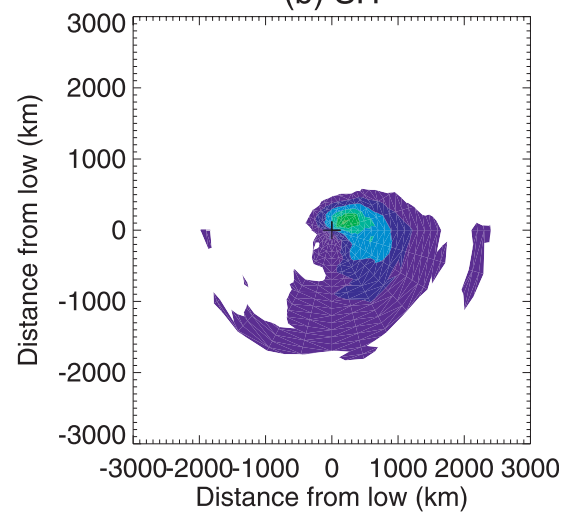

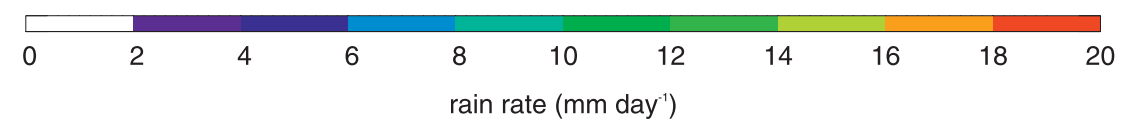

FIG. 16. Composites of AMSR-E precipitation rates for (a) $\mathrm{NH}$ and (b) SH. 
Acknowledgments. This work was supported by NASA CloudSat Science Team Grant NNX10AM20G. The authors thank James Booth and Mike Bauer for their very helpful comments. We are grateful to two anonymous reviewers for their helpful comments.

\section{REFERENCES}

Bauer, M., and A. D. Del Genio, 2006: Composite analysis of winter cyclones in a GCM: Influence of climatological humidity. J. Climate, 19, 1652-1672.

Bender, F. A.-M., V. Ramanathan, and G. Tselioudis, 2012: Changes in extratropical storm track cloudiness 1983-2008: Observational support for a poleward shift. Climate Dyn., doi:10.1007/ s00382-011-1065-6, in press.

Bengtsson, L., K. I. Hodges, and N. Keenlyside, 2009: Will extratropical storms intensify in a warmer climate? J. Climate, 22, 2276-2301.

Berry, G., M. J. Reeder, and C. Jakob, 2011: A global climatology of atmospheric fronts. Geophys. Res. Lett., 38, L04809, doi: 10.1029/2010GL046451.

Boutle, I. A., S. E. Belcher, and R. S. Plant, 2011: Moisture transport in midlatitude cyclones. Quart. J. Roy. Meteor. Soc., 137, 360-373.

Dee, D. P., and Coauthors, 2011: The ERA-Interim reanalysis: Configuration and performance of the data assimilation systems. Quart. J. Roy. Meteor. Soc., 137, 553-597.

Eckhardt, S., A. Stohl, H. Wernli, P. James, C. Forster, and N. Spichtinger, 2004: A 15-year climatology of warm conveyor belts. J. Climate, 17, 218-237.

Field, P. R., and R. Wood, 2007: Precipitation and cloud structure in midlatitude cyclones. J. Climate, 20, 233-254.

_ - A. Bodas-Salcedo, and M. E. Brooks, 2011: Using model analysis and satellite data to assess cloud and precipitation in midlatitude cyclones. Quart. J. Roy. Meteor. Soc., 137, 15011515.

Gordon, H. N., and J. R. Norris, 2010: Cluster analysis of midlatitude oceanic cloud regimes: Mean properties and temperature sensitivity. Atmos. Chem. Phys., 10, 6435-6459.

Govekar, P. D., C. Jakob, M. J. Reeder, and J. Haynes, 2011: The three-dimensional distribution of clouds around Southern Hemisphere extratropical cyclones. Geophys. Res. Lett., 38, L21805, doi:10.1029/2011GL049091.

Graham, N. E., and H. F. Diaz, 2001: Evidence for intensification of North Pacific winter cyclones since 1948. Bull. Amer. Meteor. Soc., 82, 1869-1893.

Haynes, J. M., T. S. L'Ecuyer, G. L. Stephens, S. D. Miller, C. Mitrescu, N. B. Wood, and S. Tanelli, 2009: Rainfal retrieval over the ocean with spaceborne W-band radar. J. Geophys. Res., 114, D00A22, doi:10.1029/2008JD009973.

_ C. Jackob, W. B. Rossow, G. Tselioudis, and J. Brown, 2011: Major characteristics of Southern Ocean cloud regimes and their effects on the energy budget. J. Climate, 24, 5061-5080

Hewson, T. D., 1998: Objective fronts. Meteor. Appl., 5, 37-65.

Kawanishi, T., and Coauthors, 2003: The Advanced Microwave Scanning Radiometer for the Earth Observing System (AMSRE), NASDA's contribution to the EOS for global energy and water cycle studies. IEEE Trans. Geosci. Remote Sens., 41, 184 194.
Klein, S. A., and C. Jakob, 1999: Validation and sensitivities of frontal clouds simulated by the ECMWF model. Mon. Wea. Rev., 127, 2514-2531.

Lambert, S. J., and J. C. Fyfe, 2006: Changes in winter cyclone frequencies and strengths simulated in enhanced greenhouse warming experiments: Results from the models participating in the IPCC diagnostic exercise. Climate Dyn., 26, 713-728.

Lau, N.-C., and M. W. Crane, 1995: A satellite view of the synopticscale organization of cloud properties in midlatitude and tropical circulation systems. Mon. Wea. Rev., 123, 1984-2006. , and _ 1997: Comparing satellite and surface observations of cloud patterns in synoptic-scale circulations systems. Mon. Wea. Rev., 125, 3172-3189.

Mace, G. G., 2010: Cloud properties and radiative forcing over the maritime storm tracks of the Southern Ocean and North Atlantic derived from A-train. J. Geophys. Res., 115, D10201, doi:10.1029/2009JD012517.

Q. Zhang, M. Vaughan, R. Marchand, G. L. Stephens, C. Trepte, and D. Winker, 2009: A description of hydrometeor layer occurrence statistics derived from the first year of merged CloudSat and CALIPSO data. J. Geophys. Res., 114, D00A26, doi:10.1029/2007JD009755.

Marchand, R., G. G. Mace, T. Ackerman, and G. Stephens, 2008: Hydrometeor detection using CloudSat-An earth-orbiting 94-GHz cloud radar. J. Atmos. Oceanic Technol., 25, 519-533.

Naud, C. M., A. D. Del Genio, and M. Bauer, 2006: Observational constraints on the cloud thermodynamic phase in midlatitude storms. J. Climate, 19, 5273-5288.

,,--- , and W. Kovari, 2010: Cloud vertical distribution across warm and cold fronts in CloudSat-CALIPSO data and a general circulation model. J. Climate, 23, 3397-3415.

Rienecker, M. M., and Coauthors, 2011: MERRA: NASA's Modern-Era Retrospective Analysis for Research and Applications. J. Climate, 24, 3624-3648.

Simmonds, I., and K. Keay, 2000: Variability of Southern Hemisphere extratropical cyclone behavior, 1958-97. J. Climate, 13, 550-561.

Sinclair, V. A., S. L. Gray, and S. E. Belcher, 2010: Controls on boundary layer ventilation: Boundary layer processes and largescale dynamics. J. Geophys. Res., 115, D11107, doi:10.1029/ 2009JD012169.

Solomon, S., D. Qin, M. Manning, M. Marquis, K. Averyt, M. M. B. Tignor, H. L. Miller Jr., and Z. Chen, Eds., 2007: Climate Change 2007: The Physical Science Basis. Cambridge University Press, 996 pp.

Stephens G. L., and Coauthors, 2002: The CloudSat mission and the A-TRAIN: A new dimension of space-based observations of clouds and precipitation. Bull. Amer. Meteor. Soc., 83, 1771-1790.

Trenberth, K. E., and J. T. Fasullo, 2010: Simulation of present-day and twenty-first-century energy budgets of the southern oceans. J. Climate, 23, 440-454.

Wentz, F., and T. Meissner, 2004: AMSR-E/Aqua L2B global swath ocean products derived from Wentz algorithm V002, 2006-2009. National Snow and Ice Data Center, Boulder, CO, digital media. [Available online at http://nsidc.org/data/ae_ocean.html.]

Wilheit, T., C. Kummerow, and R. Ferraro, 2003: Rainfall algorithms for AMSR-E. IEEE Trans. Geosci. Remote Sens., 41, 204-214.

Winker, D. M., M. A. Vaughan, A. H. Omar, Y. Hu, K. A. Powell, Z. Liu, W. H. Hunt, and S. A. Young, 2009: Overview of the CALIPSO mission and CALIOP data processing algorithms. J. Atmos. Oceanic Technol., 26, 2310-2323. 